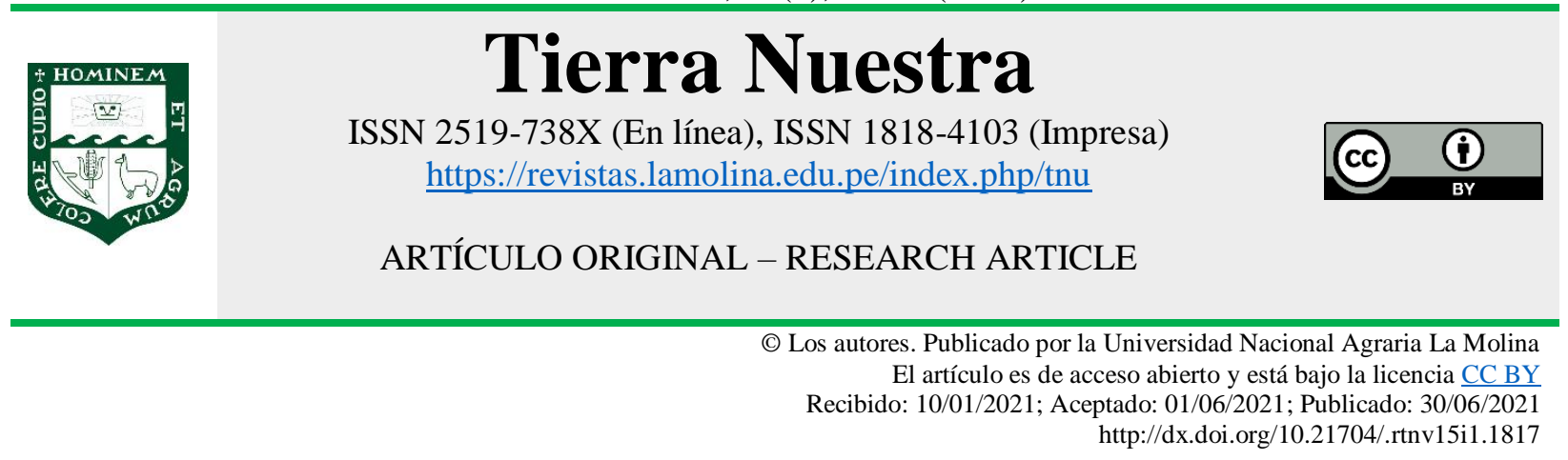

\title{
Estudio etnolingüístico de los indigenismos de Huarochirí. Léxico inédito en el a'karu de Julio C. Tello
}

\section{Ethnolinguistic study of the aboriginal words of Huarochirí. Unpublished lexicon in the a'karu of Julio C. Tello}

\author{
Emérita Escobar Zapata ${ }^{1,2 *}$ \\ * Autor de correspondencia: escobar@lamolina.edu.pe
}

\section{RESUMEN}

El principal propósito de la presente investigación es analizar, desde la perspectiva etnolingüística y la lingüística cultural, voces léxicas que son parte del vocabulario a'karu de Julio C. Tello ([1908] (1926) 1940), quien las categoriza como indígenismos de Huarochirí. Estas unidades léxicas son verbos y sustantivos provenientes de las lenguas andinas jacaru, aimara o quechua, predominantemente, adaptadas a las normas ortográficas y patrones fonológicos y morfológicos del castellano. Por ejemplo, "Chipar. f. 993r. |chhipar| Envolver. < jacaru chipa. Envoltura de cuero de vaca con muchos agujeros y lazos o sogas delgadas que sirven para transportar los quesos que se acomodan en ellos con las hojas de Gynerium".

Palabras clave: Léxico jacaru, etnolingüística, lingüística cultural, indigenismos, Huarochirí.

\section{ABSTRACT}

The main purpose of this research is to analyze, from the ethnolinguistic and cultural linguistic perspective, words that are part of the a'karu vocabulary of Julio C. Tello ([1908] (1926) 1940), who categorizes these words as remnants of aboriginal tongues in Huarochiri. These lexical units are verbs and nouns that have been structured from verb roots in andean languages like jacaru, aimara or quechua, predominantly, adapted to the ortographic, phonological and morphological patterns of Spanish. For example, "Chipar. F. 993r. | chhipar | Wrap. < jacaru chipa. Cowhide casing with many holes and thin ties or ropes that serve to transport the cheeses that are accommodated in them with the Gynerium leaves".

Keywords: Jacaru lexicon, ethnolinguistics, cultural linguistics, indigenisms, Huarochirí.

Forma de citar el artículo (Formato APA):

Escobar, E. (2021). Estudio etnolingüístico de los indígenismos de Huarochirí. Léxico inédito en el a’karu de Julio C. Tello. Tierra Nuestra. 15(1), 52-68. http://dx.doi.org/10.21704/rtn.v15i1.1817

${ }^{1}$ Universidad Nacional Agraria La Molina, Lima, Perú. Email: escobar@lamolina.edu.pe

${ }^{2}$ Universidad Nacional Mayor de San Marcos, Lima, Perú. Email: eescobarz@ unmsm.edu.pe 
[...] el conjunto de los rasgos materiales y no materiales que definen a una sociedad en un momento dado halla su expresión particularmente en el nivel léxico de la lengua, el más directamente ligado al mundo de los símbolos, lo real y lo vivido. [...], caracterizado por su perenne posibilidad de cambio, de reducción o ampliación, de variación en sus contenidos semánticos y en las relaciones estructurales [...] ( $c f$. Alfredo Torero, 1974, 2007, p.56).

\section{Introducción}

El Perú, al igual que muchos otros países del grupo andino, se destaca por la diversidad lingüística y por mostrar un escenario donde el contacto de lenguas, aunque data de épocas precoloniales, se fue acentuando durante el periodo colonial, marcado por la llegada de los invasores españoles con su idioma. Desde entonces, sociolingüística y etnolingüísticamente, se ha evidenciado el surgimiento de diversos fenómenos como el bilingüismo, la diglosia, las interferencias lingüísticas, los préstamos; pero también uno de los de mayor visibilidad ha sido el lingüicidio o desaparición de lenguas originarias, proceso que aún no ha concluido, y en el que vemos actualmente algunas en peligro de extinción ${ }^{1}$. Aun cuando ya se han venido implementando políticas lingüísticas orientadas a salvaguardarlas, revitalizarlas, difundirlas y revalorarlas, los resultados siguen siendo preocupantes $\mathrm{y}$, desde luego, se demanda un mayor compromiso interinstitucional para lograr cambios favorables, visibles y medibles.

En el presente estudio se propone, desde una perspectiva etnolingüística y de la lingüística cultural, analizar un conjunto de voces léxicas tales como cuchiquear, cashpar, chipar, cullicar, listados como indigenismos de Huarochirí por el arqueólogo J. C. Tello, cuyas raíces provienen de lenguas andinas (quechua, jacaru o aimara), reacomodadas a las normas y patrones ortográficos, silábicos y morfológicos del castellano; en otros casos, llama la atención la presencia de voces toponímicas, por ejemplo, waskayanga, chauquenga, entre otros, cuya explicación podría aportar en la dilucidación del complejo escenario linguístico que existió en el antiguo Huarochirí.

Como sabemos, el documento de mayor trascendencia que aporta una valiosa información sobre la complejidad linguística del antiguo Huarochirí proviene del interés del extirpador de idolatrías Francisco de Ávila ${ }^{2}$ (1608); nos referimos al Manuscrito Quechua de Huarochirí ${ }^{3}$, que trata de las tradiciones antiguas de los pobladores de esta provincia y en el que se afirma que se hablaba la lengua general, que era más comprendida por las mujeres (cf. Gerald Taylor, 2008).

Metodológicamente, nos planteamos las siguientes preguntas que guían la presente investigación ${ }^{4}$ :

1) ¿Qué filiación lingüística predomina en los indigenismos de Huarochirí aportados por J.C. Tello?

2) Desde la perspectiva etnolingüística y/o la lingüística cultural, ¿qué refleja la temática a la que hace referencia el léxico indigenista de Huarochirí?

3) ¿En qué medida el léxico indigenista de Huarochirí refleja parte de la realidad lingüística que existió antiguamente en esta región o área?

Respecto de la organización del presente estudio, éste se estructurará a partir de los siguientes rubros: 1) criterios que definen un indigenismo; 2) el marco teórico-conceptual; 3) los aspectos metodológicos: 4) definición de los indigenismos; 5) los indigenismos de Huarochirí; 5.1) indigenismos de uso común; 5.2) indigenismos toponímicos; 6) comentarios y reflexiones; finalmente, las conclusiones y referencias bibliográficas.

En el presente trabajo de investigación, nos interesa definir y someter al respectivo escrutinio cada una de las voces que forman parte del corpus seleccionado y también su cotejo en fuentes escritas coloniales, con la finalidad de lograr una adecuada identificación de su filiación lingüística así como una interpretación de los elementos que forman parte de cada ítem o unidad léxica.

Mi agradecimiento y reconocimiento ${ }^{5}$ al amigo el profesor Marco Ferrell, por los comentarios y sugerencias oportunas sobre este documento.

\section{Criterios que definen un indigenismo}

En primer lugar, para definir los indigenismos es necesario tener la evidencia de su procedencia de alguna de las lenguas amerindias peruanas, en este caso, 
de las andinas. Teniendo esto en cuenta, los estudiosos hacen referencia a la presencia de una impronta lingüística en esta región, particularmente, producto de la confluencia de lenguas nativas en Huarochirí, y el inevitable contacto con el castellano. En segundo lugar, identificar los patrones o normas implementados en el proceso de su adaptación o asimilación en la lengua que los adopta y adapta. En este caso, la mayoría de los vocablos que consideramos indigenismos y que así también han sido categorizados por Julio C. Tello (1908), 1926, 1940) provienen de raíces verbales o nominales de las lenguas originarias andinas (jacaru, aimara y/quechua). Estas formas se han visto afectadas por algunas innovaciones del proceso de adaptación a las estructuras ortográficas, fonológicas y morfológicas de la lengua receptora. Un menor número de casos, mantienen la forma original de la lengua autóctona o indígena. Los indigenismos en el Perú pueden evidenciar o testimoniar la existencia histórica de una lengua o variedad dialectal que ya no está vigente en la zona o área. Este es el caso de una parte de las voces cuyos étimos responden a una de las hablas de la lengua jacaru que existió en la región de Huarochirí pero que perdió su vitalidad.

\section{Marco teórico-conceptual}

2.1 Etnolingüística

La etnolingüística es uno de los campos interdisciplinarios que se propone explicar la relación entre el lenguaje y la cultura; o la relación entre el lenguaje, la cultura y el pensamiento. Ante todo, le corresponde el estudio de los hechos de una lengua en cuanto motivados por los saberes (creencias, ideas, concepciones ideológicas) acerca de las "cosas". Según Coseriu (1981), una cosa se conoce de otro modo en una comunidad y se asocia con otros fenómenos, lo cual motivará otros tipos de expresiones. El investigador rumano propone convertir la etnolingüística en una

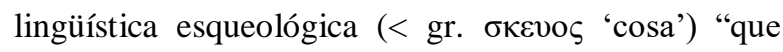
estudie la contribucción del «conocimiento de las cosas» respecto a la configuración y funcionamiento del lenguaje" ( $c f$. Coseriu, (1981: 11, en Martín Camacho (2018)). Agrega que esta disciplina debe dar cuenta de todas las formas en las que la cultura o el conocimiento de la cultura interacciona con la lengua y el uso o práctica que hacen los hablantes.

En los datos seleccionados de las voces léxicas o indigenismos de Huarochirí, se perciben evidencias de haber sido construidos, creados, a partir de una motivación propia de la cultura, es decir, según los saberes o concepciones de los hablantes, y esto es lo que pretendemos demostrar. El etnolingüista intenta describir y comprender, para sí y para los demás. el rol del lenguaje en la configuración de las formas en que los miembros de un grupo se relacionan con el mundo. Estas formas de conocimiento y del ser son las cosas con las que las identidades están hechas. Las identidades constan de significados y de configuraciones específicas de significados que pueden implementarse funcionalmente como roles a través de las prácticas comunicativas de la comunidad (cf. Philip Riley 2007: pp. 11).

Esta definición es bastante sostenible, pues claramente construye la idea medular que subyace en el área de trabajo de la etnolingüística. que es develar la cosmovisión sobre la que se construye el sistema de conceptualización del léxico y unidades lingüísticas de una determinada comunidad o grupo social, más aún cuando hay evidencias de la existencia de expresiones de un escenario cultural variopinto.

Los idiomas sirven como "bancos de memoria" para las conceptualizaciones culturales, tanto pasadas como presentes $\mathrm{y}$, como tales, proporcionan archivos interesantes para el estudio de las conceptualizaciones culturales asociadas con ellas ( $c f$. Kövecses, 2005; Palmer 1996; Sharifian et al., 2008).

\subsection{Lingüística cultural}

Es una disciplina recientemente desarrollada con orígenes multidisciplinarios que explora la relación entre el lenguaje y las conceptualizaciones culturales (cf. Sharifian 2011a, 2012, 2017). Se afirma que muchas características de los lenguajes humanos están arraigadas $\mathrm{o}$ incrustadas en conceptualizaciones culturales. La lingüística cultural se ha basado en varias otras disciplinas y subdisciplinas para desarrollar su base teórica, que incluye la psicología cognitiva, la ciencia de la complejidad, la cognición distribuida y la antropología (cf. Sharifian 2011a, 2014, 2015a; Sharifian y Palmer, 2007).

La lingüística cultural ofrece un marco teórico y analítico para investigar las conceptualizaciones y reconceptualizaciones culturales que subyacen al uso de los lenguajes humanos. En el corazón de este enfoque cognitivo se encuentra la noción de "cognición" y 
"cultura" en su relación con el lenguaje (cf. Sharifian 2009a, 2011a).

Según Frank (2015, p. 494), la cognición cultural es una forma de "cognición enactiva" ( $c f$. Stewart, Gapenne y Di Paolo, 2011) que surge como resultado de interacciones sociales y lingüísticas entre individuos a través del tiempo y el espacio ( $c f$. Cowley y ValléeTourangeau, 2013). Los hablantes muestran variaciones y diferencias en su acceso e interiorización de la cognición cultural, la cual es dinámica en el sentido de que se negocia y renegocia constantemente entre generaciones y mediante el contacto entre comunidades de habla.

\section{Aspectos metodológicos}

El corpus de datos utilizado proviene de una fuente lexicográfica inédita que estamos trabajando ( $c f$. Tello [1906] 1926, 1940). Son indigenismos huarochiranos que hacen referencia a objetos de uso cotidiano, costumbres y creencias vigentes en las primeras décadas del siglo XX; es bastante probable que algunos de estos elementos ya no se escuchen actualmente.

Esquema a seguir en la presentación de las voces indigenistas: presentación del vocablo étnico tomado de la fuente, seguida del N. ${ }^{\circ}$ de folio; inmeditamente, entre barras perpendiculares, va nuestra interpretación ortográfica, seguida de la glosa propuesta por el autor. Con el fin de identificar la etimología u origen lingüístico de cada unidad léxica, se procederá a la revisión de los vocablos en la documentación lexicográfica colonial y contemporánea de las lenguas andinas, tomando como información inicial las glosas aportadas por J. C. Tello. Finalmente, se explicará cómo se adaptan al castellano.

\section{Indigenismos 6}

Una breve definición correspondería a toda palabra de procedencia indígena que pasa a la lengua invasora. Se aplica, generalmente, a voces de lenguas no europeas: indigenismos americanos, africanos, etc. Una palabra es indigenismo con relación a la lengua invasora hablada, precisamente donde vivió o vive la lengua dominada. Por ejemplo, petaca, cóndor, chocolate son indigenismos en el español de América; con relación al español peninusular son americanismos ( $c f$. Lázaro Carreter (1953). Por su parte, José Joaquín Montes Giraldo (1970: p. 106), al hablar de americanismos diacrónicos, considera que a los indigenismos se les llama así si proceden de las lenguas aborígenes americanas y si su uso es histórico genético.

Según el $\mathrm{DLE}^{7}$, un indigenismo se define como un «Vocablo, giro, rasgo fonético, gramatical o semántico que pertenece a alguna lengua indígena de América o proviene de ella». Indudablemente, el mestizaje cultural también involucró el mestizaje lingüístico, incorporando parte de los elementos de la lengua hispana a las lenguas indígenas, y como resultado se cimentó un rostro más abonado a la diversidad lingüística y cultural.

En el Diccionario Breve de Mejicanismos, se define un indigenismo como «regionalismo lingüístico americano, palabra o frase de origen indígena utilizada en el español de algún país de América» ( $c f$. Guido Gómez de Silva).

Hasta aquí, como ha podido apreciarse, es innegable que la fuente u origen de un indigenismo siempre es un vocablo propio de una lengua originaria (azteca, guaraní, maya, quechua, aimara, jacaru, cauqui, entre otras) que es asimilada por el castellano.

\section{Los indigenismos de Huarochirí}

En 1926, J. C. Tello, al dar cuenta del tipo de cerámica negra que extrajo de una caverna próxima a Tupe, provincia de Yauyos, semejante en estilo a la Chavín y quizá mejor a cierto tipo de cerámica negra en Paracas; también señala que allí los nativos conservan todavía en toda la pureza muchas de sus antiquísimas costumbres y la lengua nativa ak'aro o kauki que parece ser la primitiva lengua andina. ( $c f$. Antiguo Perú, 1929: p. 98).

\section{Introducción}

Históricamente, las poblaciones indígenas son parte de un legado histórico-cultural, herederas de culturas milenarias como la wari, la preínca o la inca. Con la llegada de la lengua de los conquistadores y el inminente contacto con las lenguas amerindias peruanas, se generaron, desde entonces, diversos fenómenos sociolingüísticos como el bilingüismo, diglosia, los interlectos, sustratos, adstratos, superestratos y mestizajes lingüísticos o indigenismos 
cuya estructura básica proviene de una de las lenguas originarias como el quechua, aimara, jacaru, o lenguas amazónicas, pasando por el proceso de adecuación o adaptación de las normas o patrones ortográficos, silábicos y/o morfológicos del castellano, la lengua predominante en nuesto entorno.

Centrándonos en nuestros datos léxicos, los indigenismos de Huarochirí son palabras originarias (verbos y sustantivos simples o compuestos), provenientes de las lenguas andinas, jacaru, aimara y/o quechua, que se introdujeron en el habla hispana de la región huarochirana, previa adaptación a la escritura, fonología y morfología del castellano, la lengua que se impusó en todo el territorio peruano.

Considerando la temática de los indigenismos que se va a presentar, podemos afirmar que existe una justificada motivación en su uso. En estos elementos léxicos se refleja gran parte de su realidad que se deduce al analizar las conceptualizaciones que designan o refieren eventos, costumbres relacionadas con el ganado, agricultura, rituales, saberes o prácticas cotidianas de la familia, en lo cual se expresa la cosmovisión o filosofía ancestral de los pobladores de esta región. Al término del escrutinio y análisis de los vocablos, se presentarán las principales carácterísticas o aspectos que definen este corpus léxico.

\subsection{Indigenismos de uso común}

El corpus léxico que presentamos a continuación es parte del Vocabulario A'karu de J. C. Tello ([1908] 1926), material que se clasifica como indigenismos de Huarochiri ${ }^{8}$. Cada entrada léxica se presenta tal como aparece con su respectivo folio y con la ortografía empleada por el investigador, seguida de la designación o glosa.

En el presente estudio intentaremos indagar la filiación lingüística de estos vocablos y para ello se consultará la información proveniente de la documentación lexicográfica temprana y de las fuentes modernas. A continuación se presentan los datos a analizar en orden alfabético:

anchular. $f$. 1025r. |qanshular| Desyerbar las márgenes de las chacras; si se hace en el medio quitando las malas yerbas en toda la plantación o sembrío, se llama escardar ${ }^{9}$.
En el Vocabulario de Belleza encontramos el término ashuwi con el significado de deshierbar, quitar la maleza (cf. Belleza, N. 1995: p. 232).

apallanga $f$. 984v. |apallanga|. Mango de la taclla, accesorio del arado. En Huarochirí (San Damián Lahuastama y Langa).

Este vocablo es de procedencia quechua. Se ha estructurado partiendo de la raíz apa 'llevar', el sufijo lla que cumple función expletiva y -nga ${ }^{10}$ (<-nqa) es sufijo nominalizador instrumental, de donde <apallanga> (< apallanqa) significa 'lo que sirve para llevar' (en este caso el mango de la taclla que permite llevar o mover la herramienta en su conjunto). < Q *apallanqa.

autiri. $f$. 727r. |awtiri| s. pastor, síncope de awatiri en aymara. $\| 2$. Autiri. v. pastear. Ahora bien, intentando corroborar la información proporcionada por Tello, empezamos la revisión de las primeras documentaciones.

Buscando explicación, encontramos que en aimara awatiri (<ahuatiri> en Bertonio (1612) y Torres Rubio (1616)) significa 'pastor'; pero mejor coincidencia es awtiri, que tambien significa 'pastor' en jacaru ( $c f$. Belleza 1995, p. 41). < JAC-A */awtiri < awata/. Tanto en jacaru como en aimara, la raíz es awata- a la que se adhiere el sufijo agentivo -ri; la única diferencia es que en este caso la aplicación del agentivo en jacaru provoca caída de vocal y resulta awtiri en vez de awatiri en aimara. Más bien, hay que aclarar que la segunda acepción que agrega Tello sería una anomalía al incluir un derivado verbal (agentivo) del étimo en lugar del infinitivo, que es lo que correspondería (en este caso, en castellano podría ser autir). Por consiguiente, el término <autiri>, tal como se ha transcrito en el documento de J. C. Tello, responde a la pronunciación en castellano; y al asimilarse a esta lengua también se hace siguiendo sus patrones ortográficos. Tomando en cuenta el significado y la reconstrucicón de la forma, se puede colegir, por una parte, que su filiación lingüística es de origen aru, pues hasta la fecha esa palabra se incluye en los documentos lexicográficos del jacaru y aimara.

cacharpa $f$. 1150. |kacharpa|. Wato trenzado a manera de wakura muy bonito que amarra el anacu sobre el hombro y del cual enganchan sus tiranitas, aritos y piruras. 
En la documentación quechua se constata que la forma léxica kacharpa hace referencia a 'Trapos, ropas y utensilios sin valor [...]'; y kacharpákuy. v.a. arreglar bártulos. (cf. Lira J. \& Mejía M. 2008: p. 171). < Q. */kacharpa/.

camiri. $f$. 741r. v. lavar. |qamiri|. En el vocabulario de Belleza (1995: p. 145). /qama/. Lavar. Estamos ante un caso similar al de autiri, porque qamiri (< qama) 'lavador', 'el que lava' también es un participio activo agente procedente del jacaru. Considerando la regla morfofonológica que opera, en esta lengua y en aimara, el sufijo de agente -ri provoca cambio cuando la vocal precedente es /a/; así, qama 'lavar' al agregar -ri no genera la forma qamari sino qamiri. < JAC. */qamiri/ </qama/.

canchaya. $f$. 1151. |kamcha+ya|. Cuando la mazorca aparece en el momento del desporfollamiento seco listo para tostar, no igual a las otras mazorcas que se están despancando del arco.

Como en la mayoría de las voces léxicas, Tello no da cuenta de su etimología o procedencia lingüistica. Consideramos que el indigenismo <canchaya>, en cuanto a su forma se ha estructurado combinando la raíz quechua <kamcha> 'maíz tostado', 'tostar maíz' ( $c f$. Domingo de Santo Tomás 1560: p. 214; Lira \& Mejia 2008; Soto 2012; Itier 2017); y el sufijo nominal quechua -ya, del cual el Diccionario de la AMLQ (2005) ofrece ejemplos como ch'oqtaya (< ch'oqta), hatunya (< hatun), qenaya (< qena) (AMLQ 2005). < Q. *kamcha

cashe. $f$. 1161r. Herramienta de agricultura de madera para escarbar la papa durante la cosecha. 2 . casho. $f$. 1037r. Palo de madera resistente del tamaño de un bastón aguzado en un extremo que sirve para sacar las papas (dist. de Huarochirí) y Yauyos.

Según la pesquisa realizada sobre este vocablo, hasta la década de los setenta los pobladores de Huarochirí todavía hacían referencia a esta herramienta con la misma forma casho. s. Palo mediano terminado en punta que sirve para sembrar el maíz. ( $c f$. Núñez Vargas, Leopoldo 1992: p. 294), que corresponde en el quechua de Áncash a: "kashu. [...] Instrumento para sacar tubérculos" ( $c f$. Parker y Chávez 1976, pág. 78). En cuanto a <cashe>, es variación de <casho> $(</ \mathrm{kashu} /)$ producida por el cambio /u/ > /i/ kashu > kashi; y de este último sale <cashe>. < Q. $/$ kashi/ $>/$ kašu/. cashpar. $f .1024$ r. |qhashpar|. Chamuscar o quemar los pelos de las patas y cabeza de los carneros o chanchos que han de comerse con toda la piel. En Langa se usa la forma Ronjar. \|2. caswar ${ }^{11}$. $f .1150$ r. Ikaswarl. Tostar las patas del carnero y llamas para quitarle la lana y los casquitos.

Tras una revisión de las fuentes lexicográficas tempranas del aimara y quechua, ubicamos el verbo aimara <kasparatha> chamuscar. (cf. Bertonio, [1612] 2005-2006: p. 173) así como la entrada quechua <Kazpani> Chamuscar o tostar, perdigar ( $c f$. Gonçález Holguín [1608] (1952) 2007: p. 416).

Igualmente, está vigente en las fuentes modernas. Parker y Chávez (1976), en su Diccionario Quechua Áncash-Huailas, traen “qashpay. [...] tr. Quemar (pelo), chamuscar". Así, en el Vocabulario jacaru encontramos los siguientes datos: "qhaspa. v. Raspar la yuca para exponerla al sol. \|.Qhaspshu. v. Chamuscarse (vello, pelo, plumas)." ( $c f$. Belleza 1995: p. 152). En Itier (2017), se registra "qaspa ${ }^{1}$ (CHAN: qaspa; INCA COLL: q'aspa) ligeramente asado, soasado" (cf. Itier, 2017: p. 175). Finalmente, en el diccionario etimológico de peruanismos de Calvo Pérez se encuentra "caspar. del quechua q'aspay 'asar, tostar al fuego, socarrar' ('chamuscarse al fuego, quemarse por la parte exterior'). 'carne poco asada"' ( $c f$. Calvo Pérez 2014: p.159). A la luz de los datos consideramos que el étimo de <cashpar>, por la presencia de la sibilante palatal /š/, nos acerca más al quechua norcentral. Al ser asimilada por el castellano de Huarochirí, se habría adaptado a la ortografía y morfología verbal de esta lengua, acabando en su forma infinitiva. < Q. */qašpay/.

cóchika. $f$. 1152. |qúči.ka|. Terreno a donde no se puede hacer correr agua, pero se siembra por si acaso la lluvia le acompañe hasta su madurez.

Proponemos que este vocablo está formado por la palabra quechua qhuči [qhoči] 'manantial encharcado' y 'sitio pantanoso' (Consejo Educativo de la Nación Quechua "CENAQ" (s/f)) más el sufijo nominal formativo -ka, del que hay numerosos ejemplos en el Diccionario de la AMLQ: mañaka (< maña-), runaka (< runa), sach'aka (< sach'a), etc. Q. /qhuči/ +/-ka/.

cuchchicachar. $f .1027$ r. Romper una soga o pita con los dientes o entre dos objetos duros cualesquiera. los dientes o entre dos objetos duros cualesquiera. 
Aquí tenemos el verbo quechua $k u c ̌ u$ - 'cortar' más el sufijo -ykača, que indica reiteración o repetición; a kučuykača ( $>$ kučiykača) se adhiere el sufijo castellano -ar y se obtiene <cuchchicachar >. < Q. $/<$ kučiykačay < kučuykačay/.

cuchiquear. $f$. 740r. |kuchi.kiar| Cortar la soga (en el habla de Huarochirí).

Según Tello, esta palabra proviene del verbo <cuchutha> /kuču.tha/ en Gonçález Holguín, que significa 'cortar', como se encuentra hoy tanto en el jacaru (kuču) como en el aimara (kučuña). No dice Tello nada del segmento <quear>, que puede explicarse teniendo en cuenta la siguiente secuencia de cambios: kuchukuy > kuchukiy (desredondeamiento inducido por /y/, como sucede en lugares del dpto. de Áncash) > kuchikiy (por armonía vocálica condicionada por -kiy); a la base kuchikiy se adhiere el sufijo castellano -ear y el resultado es <cuchiquear>. De lo mencionado por el estudioso huarochirano, se desprende, primero, su hipótesis sobre el origen etimológico de esta voz adaptada a los patrones, ortográficos, silábicos y morfológicos del castellano; segundo, su conocimiento del emparentamiento entre ambas lenguas $y$, finalmente, la evidencia de que la lengua jacaru también se hablaba en esta región y, posiblemente, sobreviviría hasta las décadas finales del siglo XIX, pues ya había empezado su asimilación de varias voces al castellano como testimonio de la influencia cultural de estas voces originarias.

Finalmente, cabe señalar que el origen etimológico si bien es cierto que kuchu- es raíz quechuamara, del quechua en particular se obtiene mejor explicación de los procesos de cambio fonológico. < Q. /kučikiy/ < /kučukuy/.

cuchupar, cuchpar o cuspar. $f .1038$. |kuchpar| |kuspar|. Primer cultivo que se hace con las plantas de sembrío con el objeto de aflojar el terreno de secado después que han pasado las lluvias y de desyerbarlo.

En referencia a esta voz, Tello señala la siguiente cita:

Bernabé Cobo. Historia del Nuevo Mundo p. 192. Tomo. IV. dice "Usan mucho los españoles lampas hechas de hierro en sus labranzas particularmente para desyerbar las huertas y viñas que en esta tierra llaman Cuspar".

En el diccionario del quechua Áncash-Huailas encontramos "kuspay2. HUA tr. Aporcar tubérculos."
Por otro lado, en el jacaru de los pobladores de Tupe, Ayza y Colca, encontramos kuspa. v. aporcar ( $c f$. Belleza, 1995: p. 95), lo que coincide con Áncash. Debemos reparar en que Tello pone la variante <cuchpar>, en la cual la africada palatal revelaría una antigua procedencia de una variedad semejante al quechua chanca, en la que se conserva la africada palatal /č/ en posición final de sílaba. Por ejemplo, el número cinco es pichqa en quechua chanca y $p$ 'isqa en aimara y en el aimarizado quechua cusqueño. Esto nos incvlinaría a aceptar un étimo quechua. < Q. */kučpa/ > /kuspa/.

cullicar o chacchar. $f .1038 \mathrm{r}$. |kullikar|. Mascar coca unida a la cal congona y partículas del tallo de una planta de las alturas llamada shutanca en Yauyos $\mid 2$. chutaña.

Una primera información relacionada con esta voz la registramos en la documentación lexicográfica colonial de Gonçález Holguín: “Acuni acullicuni. Comer coca (cf. Diego Gonçales Holguín [1608 (1952)] 2007: 43). Otra fuente lexicográfica que nos permitirá determinar su origen quechua es el Anónimo, en el que figura el siguiente dato: acullini, acullicuni 'comer coca'; acullichini 'darle a comer coca'; acullayani 'traer la coca en la boca'. Igualmente, en los diccionarios del quechua contemporáneo se registra el verbo " $<$ akulliy $>$. v. Masticar la coca o alguna otra yerba que alterna con <ákuy>. ( $c f$. Diccionario quechua español-quechua. Simi Taque. 2005). De manera que a la luz de los datos expuestos concluimos que este indigenismo léxico es de estirpe quechua. < Q. */aku $\lambda$ iku-y/.

chacmar. $f .1006$ r. < Q. J. |č'akmar| v. Mover el terreno que largo tiempo no ha sido cultivado.

Según los datos registrados en el jacaru actual así como en la información proveniente de fuentes lexicográficas de la lengua quechua, se trata de un vocablo compartido por ambas lenguas. Veamos qué refieren las fuentes consultadas. Siguiendo el Vocabulario JacaruCastellano, Castellano-Jacaru de Belleza (1995), ch'ajma alude a 'arar, romper la tierra y removerla (después de regar para siembra de papas en las alturas'. (cf. Belleza, 1995: p. 51). Por su parte, Iturrizaga (2010) refiere que ch'ajma se llama así a la tierra mostrenca, silvestre, suelo nunca cultivado, sin dueño y forestado naturalmente. $\| 2$. Ch'ajmaya. Fue la acción humana de convertir la tierra silvestre en doméstica, 
tierra nunca cultivada en productiva, tierra sin propietario convertida como propiedad de una organización comunitaria e igualitaria de Mark Jaqi. [...]. (cf. Iturrizaga, 2010: pp. 189-191).

Ahora bien, en lo que respecta al quechua, una fuente consultada es la de Antonio Ricardo, en la que se ubican dos entradas relacionadas, chacmani. romper la tierra para sembrar. chacmay pacha. Tiempo de romper la tierra ( $c f$. Antonio Ricardo, Año M.D.LXXXVI). En Gonçález Holguín, chacmani significa desmontar o romper la tierra para sembrar o cualquier lauor ( $c f$. Diego Gonçález Holguín [1608 (1952)] 2007: 43). Finalmente, también se evidencia su presencia en el quechua moderno" ${ }^{12}$. Así pues, encontramos "Chakmay. Roturar la tierra para el cultivo". ( $c f$. Clodoaldo Soto 2012: p. 236). < Q. JAC. */chakma/.

chancullar. $f$. 992r. |chanqullar|. V. Matar animales y esconderlos debajo de piedras.

En Belleza (1995), se registran lo siguiente: “chanqi (1) v. golpear con piedra o martillo. ||chanqshu. v. golpear con piedra o martillo" (cf. Belleza, 1995: 46). En este caso, a la raíz verbal jacaru /chanq-/ se le ha añadido el sufijo verbal combinado con -ulla, tal como ocurre en los patrones de formación de derivación verbal en el español. Por ejemplo, de la palabra <mascar> se ha creado la forma derivada $<$ mascullar $>$. $<$ JAC. */čanqi/.

chanchaya. $f$. 1149. Vestido hilachoso y viejo. < |thántay| |thantáyay|. En el presente caso, se trata de una unidad léxica proveniente del quechua sureño que ha sido afectada por el proceso de africación de la oclusiva dental aspirada $(/ \mathrm{th} />/ \check{c} /)$, como se puede ilustrar con los casos del aimara pataka 'cien' y quta 'lago, laguna' frente a sus cognados quechuas pachak y qucha. Esto en cuanto a la raíz, y respecto del segmento -ya decimos que es un sufijo nominal caracterizador, explicado en canchaya.

chapin o chapina. $f .1006$ r. |chapin o chapina| Persona que tiene los pies torcidos de modo que a la posición vertical, forman un ángulo abierto hacia atrás. No es raro encontrar personas chapinas en el dist. de Huarochirí dependiente de esta deformidad.

Este vocablo es un americanismo. En el Diccionario de la Real Academia se ubica la entrada "chapín”, na. Adj. 2. Col. y Hond. patojo. En Guatemala, "chapina que tiene los pies torcidos". chiquillar. $f$. 993r. Asegurar al ternero para ordeñar á la madre.

Este vocablo es de origen quechua: en el Diccionario de la AMLQ tenemos “chikiy. v. Apartar de la madre una cría de vacuno para que no siga mamando y así poder ordeñar. $<$ Q. </čikiy/.

chochocar. $f$. 797r. |chuchuqa+-ar|. Palabra indígena. Hacer secar la mazorca de maíz cuando no está madura para aprovecharla en cancha o máchica. Se le conoce porque presenta arrugas a falta de harina. También se chochocan los maíces a falta de agua y por el calor tiene que secarse sin terminar su madurez.

En Gonçález Holguín, chucchucca hace referencia al maíz cocido y pasado al sol que es como arroz ( $c f$. Gonçález Holguín, 1608: p. 118). Asimismo, en el Vocabulario de Belleza (1995: p. 49), la voz chuchuqa ${ }^{13}$ se define como "Maíz cocido y puesto a secar". Finalmente, en la documentación lexicográfica aimara de la época colonial, se incluye la voz chuchuqa: "Mazorca de maíz cocido y seco al sol" ( $c f$. Bertonio, [1612] 1993: p. 217).

Hasta aquí, en cuanto a la procedencia lingüistica del indigenismo, las fuentes consultadas nos llevan a afirmar que el vocablo <chochocar> se ha remodelado o reestructurado a partir de la raíz nominal chuchuqa, registrada tanto en el quechua como en jacaru; por un lado, convirtiéndola en verbo; y, por otro lado, cambiando el timbre vocálico de la vocal /u/ > /o/, que sería más semejante al castellano, donde no existen voces léxicas que muestren la combinación de la africada palatal seguida de la vocal alta /u/ en dos sílabas seguidas, pero sí con $/ \mathrm{o}$. < Q. A. JAC. */čučuqa/.

chuchumar. $f .1149$ r $(f .994 r)$. |čučumar|. Amarrar a la criatura o fijarla a la cuna amarrándola las manos y envolviéndola con bayetas. Envoltorio que se le hace a los bebecitos para acomodarlos en la cuna y ponerlos en quietud.

Es posible que las dos primeras sílabas de chuchumar deriven de la hoy desusada expresión "hacer tutu" ('dormir', en lenguaje infantil). Como referencia, señalamos que por cambios fonéticos puede resultar una alternancia como tutuy chuchuy 'mamar' (AMLQ 
2005); así, de tutu habría surgido chuchu en Huarochiri, lo que explica al menos una parte de la palabra chuchumar.

chumir. $f .1149$ r. |chumir|. Se le dice a los bebesitos para que duerman.

En este caso es adaptación del verbo castellano /dormir/, en lenguaje infantil.

huahuaicar. $f .1018$ r. |wawaykar|. Envolver o cubrir la cabeza. $\| 2$. wawaicar. f. 1049r. |wawaykar|. Cubrir la cabeza con una manta de bayeta.

Tello también añade la siguiente construcción: “huahua icauel. $f .1017 \mathrm{r}$. Que tiene la cabeza cubierta con un pañuelo o manta." Esta información por Tello nos permite, en primer lugar, observar la presencia de una alternancia desde el punto de vista ortográfico de la raíz /wawa/ 'bebé, niño pequeño'; semánticamente, se trata de una metonimia para referirse a la cabeza del bebé, a esta raíz que sería de filiación quechua-aru, le sigue la raíz verbal del jacaru /aylla/ 'envolver', cubrir, y su adaptación a los patrones tanto ortográfico como morfológico de la forma infinitiva, en castellano.

huahuayar. $f$.1016r. |waway-ar| Llorar a gritos. Se aplica también a los perros.

En jacaru, con sonido algo similar, existe la entrada léxica wayñi. Llorar a gritos (cf. Belleza, 1995: p. 259). < J. */wayñi/ llorar, aullar.

huantiri. f.829r. |wanti.ri|. cargar algún objeto. De aquí el origen de Huantir en Huarochirí. Cargar en una frazada y la costumbre de hacerlo, etc.

En el Vocabulario jacaru de Belleza (1995), se registra "wantu. cargar con ambas manos" y su derivado wantiri 'cargador' ( $c f$. Belleza, N. 1995: p. 219), que se refleja claramente en <huantiri>. Fonológicamente, el cambio de timbre vocálico, en este caso, de /u/ $>/ \mathrm{i} /$ es frecuente en esta lengua andina, de alli que wantu $>$ want + sufijo agentivo -ri. < JAC. */wantiri/ </wantu/.

huismir. $f$.1019r. |wismir|. Orinar en Huarochirí. En el Lexicón o Vocabulario de la Lengua General del Perú, de Domingo de Santo Tomás, se registra la palabra <ismaynin> que significa 'orín de hierro'; se asociaría igualmente la voz <Ysppay> (cf. Diego Gonçález Holguín [1608 (1952)] 2007:....). o 〈ispay> 'orinar' tal como se incluye en los diccionario del quechua moderno.

En efecto, este indigenismo es de procedencia quechua < Q. */ismay/, tal como nos informa Domingo de Santo Tomás. En su asimilación al idioma castellano, el término habría pasado por un proceso de diptongación en posición inicial de palabra así como una adaptación de la sílaba final en la que se observa un reacomodo del timbre vocálico.

kallhuiri. $f$. 903v. |qallwiri| Cultivar la sementera lo que en Huarochirí se dice Kuspar. Véase. cuchupar, cuspar o cuchpar.f.1038r.

Un dato relacionado con este vocablo lo encontramos en Taylor (2008), véase el siguiente texto en el que se destaca (con negritas nuestras) la forma kallpa: "Tukuy huk waranqa Quinti ñisqa kallpapurqan chay Macahuisa upyanqanpaq" ("una huaranca de los quinti cultivaba una chacra llamada Yamlaca para que Macahuisa tuiviese chicha para beber' ( $c f$. Taylor, 2008: p. 182).

Llama la atención la transcripción de Taylor con la oclusiva velar, que sería representación ortográfica de uno de los procesos que se han evidenciado en las variedades quechua de esta zona, donde /q/ > /k/. Siendo así, interpretamos que en este caso kallpa de Taylor haría referencia a /qallpa/, que semánticamente se relaciona con la idea de 'aporcar la tierra'. Indudablemente, este vocablo respondería a la realidad linguiística del antiguo Huarochirí, en el que se puede comprobar la presencia de voces que demandan una interpretación desde el punto de vista fonéticofonológico. Uno de estos cambios es el relacionado con la oclusiva postvelar /q/. Así, en Gonçález Holguín registramos dos datos relacionados con la voz que estamos analizando y que sugieren el origen del vocablo, donde el segmento postvelar se ha innovado a través del proceso de aspiración; es decir, /q/ > /h/:

- hallmani aporcar desheruando la primera vez.

- Hallmascca harascca. Aporcado assi.

En efecto, examinando y cotejando los datos de Tello con los proporcionados por Gonçález Holguín, nos permitimos reconstruir el vocablo objeto del presente estudio, con el étimo quechua */qallpa/. Por su parte, Belleza (1995) incluye en el Vocabulario JacaruCastellano, la raiz verbal kallwi "aporcar por segunda 
vez (quitar mala hierba, reforzar con tierra la raíz o tallo de las plantas y preparar la acequia); s. segundo aporque" ( $c f$. Belleza, 1995: p. 88). Cierto es que la segunda sílaba del jacaru empieza con /w/, no con /p/ como en kallpapurqan, pero el mismo Taylor, en nota al párrafo 1 del Segundo suplemento, cita un documento en que al pelo crespo llamaban <huarca $>$ o <uarca> en lugar de <parca>, lo que muestra un caso de cambio /p/ $>/ w /$. Finalmente, en un documento del quechua cuzqueño, se registra: "Qallpa. s. Agri. Tierra removida después del escarbe. EJEM: papa qallpa, tierra donde se cosecha papa." (AMLQ 2005).

Es probable que en la etapa que corresponde, según Torero, al segundo foco de expansión del quechua se habrían generado cambios en estas hablas quechuas de la región de Huarochirí, uno de estos es la confusión de las oclusivas postvelar y velar. Asimismo, otro factor importante es el contacto con una de las variedades del jacaru, que por entonces existía y era parte de la complejidad multilingüe en la zona. De manera, que /kallwiri/ tendría en la raíz la forma quechua * qallpa > qallwa > kallwa > kallwi; a lo que se añade — como en huantiri, camiri y autiri- el sufijo aru agentivo -ri y de donde sale kallwari. < JAC. /kallwi/.

lucshir llukushiral. $f .1150$ r. Sacar los cuerecitos de las llamitas, vicuñas, zorritos y vizcachas para rellenarlo con paja y sirva de copina a los bailarines ingas.

Esta palabra guarda relación con el dato registrado en Gonçález Holguín: "Llustini [...] descortezar árbol o desollar o desnudar" y con lluch 'uy 'despellejar', cuya primera sílaba, en este caso, /llu/ se innovó con una africada "ch'utkiy [...]. Despellejar; sacar la corteza" (Cenaq s/f).

macharaco. $f .1150 .<$ Q. |pacha+ráqay|. s. Persona que nunca se viste bien a pesar que puede hacerlo. Igualmente, Tello incluye en la sección zoónimos, la voz léxica macharaka. $f$. 1163r. Pájaro de plumaje andrajoso muy pocas veces canta, gorrero de los alimentos de los bebes.

En este caso, el vocablo macharaco se crea a través del mecanismo semántico de la metáfora; así, a partir de la descripción del pájaro (su plumaje "andrajoso"), se va a conceptualizar a la persona, es decir, al macharaco. El primer componente de la palabra macharaco, que es macha, podría explicarse por el quechua, puesto que la raíz macha- significa 'emborracharse'; pero no hay seguridad de que el significado de la raíz sea pertinente para explicar macharaco (¿podría más bien ser una denominación onomatopéyica del canto del ave?). En cuanto a la forma silábica, existen el ave manaqaraku y la mariposa taparaku (AMLQ 2005).

millwir $f .1153 \mathrm{r} .<$ J. |millwi+ r|. Retorcer el hilo de lana para los llanques (PIHCH).

Al indagar sobre el origen de este indigenismo, recurrimos el Vocabulario jacaru de Belleza (1995), que incluye el verbo millwi 'enrollar, envolver'. ( $c f$. Belleza, N. 1995: p. 219). Considerando los datos consultados hasta aquí, sostenemos que étimo proviene del jacaru $<*$ JAC. /mi $\lambda$ wi/ al que se le añadió la forma infinitiva del castellano.

orushe. $f$. 1153. Dícese al carnero que de nacimiento no tiene oreja o apenas se le ve. ¿cuáles son los componentes de esta voz indígena? En el jacaru se registra el sufijo <-wishi> que significa 'sin', por ejemplo, wilwishi 'sin sangre', warmwishi 'sin esposa'. En este caso, orushe sería un híbrido castellano-jacaru, resultado de la combinación del fragmento inicial del sustantivo oreja, es decir, <or> seguida del sufijo jacaru -wishi, con la respectiva adaptación a la norma ortográfica y silábica del castellano y vía el proceso semántico de metonimia hace referencia al animal con esta característica.

paukalero. $f$. 1153. Obrero especialista en techar las esquinas de los techos de paja. Estamos ante un indigenismo creado a partir de la raíz nominal quechua pawkar 'apellido de origen incaico' y nombre de un pájaro de la selva (Cacicus cela), conocido por hacer sus nidos colgantes de una rama.

pichilinque. $f$. 1150 . Bebecito completamente desnudo. En el culle se registra la palabra <pichilingo> susceptible ( $c f$. Pantoja I., 2000: p. 94). PICHILINGUE. Ahora bien, dos datos asociados a este vocablo nos proporciona el mismo J.C. Tello: pichi: Perrito pequeño y pichichiu: Se le dice al gorrión.

Intentando una explicación consideramos que pichilinque es una forma compuesta cuyo primer elemento <pichi> designa algo pequeño, aplicable a los 
animales y niños; en este caso, a los bebés, seguida del sustantivo escuincle, cuya forma reducida sería linque.

pishir |pishir|. $f$.1152r. Operación de distender la lana. Pishiri. Extender la lana para hilar.

En el Vocabulario Jacaru de Belleza (1995) se registra la entrada léxica $u s h i$ que significa 'lana muy suave (de alpaca)' (cf. Belleza, N. 1995: p. 184, 255). Semánticamente, esta denominación sería el resultado de una creación metonímica. Con <Pishiri>, Tello vuelve a definir con infinitivo una palabra terminada en -ri (

polucha. $f$. 1161r. Vasija lagenaria a manera de damajuana que el gollete sirve de asa.

Viene de puru (cambia a /1/ por lambdacismo) y el sufijo -cha, de posible pero no seguro valor diminutivo (véase comentario abajo), que designa a plantas que producen frutos como la calabaza o más pequeños cuyo fruto de corteza dura sirven como vasijas o cucharones (Wise 1998b: pág. 432).

<puru> s. Calabaça para agua. (cf. Gonçález Holguín [1608 (1952)] 1989: 297).

<puruña> s. Fuente, tazón de boca ancha hecha de barro. (AMLQ 2005)

En la nota al párrafo 18 del capítulo 11 del MQH (Taylor 2008) se registra lo siguiente: "El sufijo -cha no significa necesariamente un diminutivo ni un despectivo (como en quinticha huanhuacha, 11:9). Se agrega a casi todos los nombres de huacas de esta serie de la cual parece ser una terminación característica". < Q. * puru.

pushpo $f$. 1149. > Q. |phuspu|. Habas secas tostada y remojada a manera de mote. Esta voz indigenista es de origen quechua, tal como se comprueba en Lira \& Mejía, 2008, donde se registra "phuspu. f. Habas hervidas, habichuelas o pallares sancochadas [sic]". $<* \mathrm{Q}$ /phuspu/. En este caso, se mantiene muy semejante a su forma original y la adecuación se muestra solo en la vocal final, de /u/ > /o/, en el proceso de castellanización.

puyto. $f .1153 .>$ Q. |puytu| Tira tejida a manera de cinta.

Se trata de un vocablo quechua tal como se registra en la variedad sureña del Cusco. Lira \& Mejía Huamán
(2008, p. 337) incluyen "púytu. Cierta cinta policroma con figuras en rombo". $<* Q$ /puytu/.

quichiri. f.744r. |k'ichiri|. Despancar. $\| 2$. hara ${ }^{14}$ quichiri |hara k'ichiri|. Despancar el maíz.

En el jacaru actual $\boldsymbol{k}$ 'ichi significa, pellizcar, arrancar hojas del maíz; arrancar hojas de las mazorcas del maíz; despancar. ( $c f$. Belleza, 1995: p. 100). En quechua cusqueño $k$ 'ichiy significa "Sacar a pellizcones partículas, piltrafas de algo" (AMLQ 2005). Como en khallwiri, huantiri, camiri y autiri, Tello define con infinitivo palabras que terminan en ri. $<$ JAC. */k'iči/.

shangalla. Caracolitos marinos que se cuelgan en las cunas a manera de sonajas.

La estructura de este vocablo estaría constituida por dos componentes: shanga y -lla, los cuales constituyen palabra con tres sílabas con /a/, que parece común en la denominación de sonajas o cascabeles, como en “Cascauel. xacapa, o çacapa” (Santo Thomás 1560); chanrararay, challchallcha, shallallallay, chanrara (AMLQ 2005); sacapa (Gonçález Holguín 1608 y Bertonio 1612). Sería una palabra de origen onomatopéyico.

shicra $f$. 1161r. |shikra|. Bolsa de tejido de la hoja del maguey estilo red.

En este caso, se trata de una voz quechua /sikra/ 'bolsa de cabuya, de asa larga'. En el Vocabulario de Holguín, existe la forma síkra que significa 'cestilla esportilla'. (cf. Gonçález Holguín [1608 (1952)] 2007: 326). < Q. /šikra/.

tataya $f$. 1151. > Q. |tataya|. Puñado de pelo humano completamente enmarañado y especialmente de los bebés que por efecto del refriegue en las cunas se forman tatayas, y es la creencia de guardarlos para la buena suerte de los niños, y aún le cuelgan moneditas de plata para que cuando se le haga el cortapelo sea muy feliz, el padrino corta la tataya porque es el que pone una buena cantidad de dinero por su ahijado. Estas tatayitas actualmente a muchos bebes de esta localidad sus madres lo cuidan para que no se desprendan.

La explicación de Tello remite a las creencias mágicas, y en este campo intentamos explicar el significado de esta palabra. En el Segundo Suplemento del Manuscrito Quechua de Huarochirí tenemos el término ata 'el/la que nace con pelo crespo'. Como era muy raro que entre 
indios naciese alguien con pelo crespo, había ceremonias para esta situación, y a los tres años se cortaba el pelo, que era ofrendado al Sol ( $c f$. Taylor 2008). En cuanto al análisis lingüístico tenemos lo siguiente: ata más el sufijo nominal -ya (véase lo explicado en chanchaya y canchaya) da ataya, y con prótesis por asimilación regresiva tenemos tataya. $<\mathbf{Q}$. /tataya/ < /ataya/.

timpe. $f$. 1161r. |timpi|. Prendedorcito chico de plata cuya cabeza es siempre escultórica.

En el quechua de Áncash Áncash encontramos tikpi 'prendedor' (Parker y Chávez 1976, p. 171) y en Huánuco también ticpi 'prendedor' (Wise 1998a); añadamos que en Áncash (ibíd., p. 172) se registra la forma nasalizada "TIMPIY, Prender con alfiler". Postulamos el siguiente cambio: tikpi > tinpi > timpe[ii]. Otro ejemplo de nasalización de consonante (post)velar es la realización del sufijo <-raq> como <-ran> en algunos lugares de Áncash (cf. Parker 1976, p. 147).

wáchiga $f$. 1153. |wachwa|. Ave como pato de vuelo largo de las punas.

Como se mostrará al término de una revisión lexicográfica, estamos ante un zóonimo de origen quechua que se ha asimilado al castellano siguiendo las normas silábicas y ortográficas de esta última lengua. Así, wachwa 'ave palmípeda lacustre, de plumaje blanco, alas negras y patas rojas' ( $c f$. Itier, 2017: p. 230); huachua |wachwa| < *wachwa. Albatro o albatroste, avutarda: [ganso andino]. ( $c f$. Cerrón Palomino, 2019: p. 257). Igualmente, Parker, Gary, 2013: p. 136, incluye "wachwa. [...] 'ganso andino': Hls, Hnc, Aya (VPI) /wačwa/; Cuz (L). /waswa/. Al respecto, el autor señala que es más probable que el étimo, por la evidencia del huanca provenga de *wačwa.

Como ya habíamos adelantado se trata de una voz de origen quechua adaptada a los esquemas silábicos del castellano. En la lengua hispana ninguna palabra exhibe una africada /č/ en final de sílaba, de allí que se inserte la vocal alta /i/ para reestructurar las sílabas; asimismo, la semiconsonante /w/ de la sílaba final, se pronuncia como una oclusiva velar sonora, de modo que /wačwa/, ortográficamente corresponde a la forma wáchigua, simplificada como wáchiga, al insertarse la vocal alta, mantiene el acento de su forma original. $<* \mathrm{Q} /$ wačwa/. wakada. $f$. 1150. |wakada|. s. Llama hembra que solamente se cría para aprovechar su carne, engordan tanto que su carne algunos lo tuestan como chicharrones. Sacan una grasa como vaselina que lo usan como medicina para el reumatismo e hinchazones.

Como una pista, en el Vocabulario de Belleza (1995) tenemos "wakada o wakama. s. llama castrado", dato interesante, pues se sabe que los animales castrados engordan. La descripción de Tello, que remite a la llama hembra, es confirmado por José Matos (1951, citado por González Salazar 2018: pág. 150). Actualmente en Tupe llaman huacada a la alpaca juvenil o recién llegada a la adultez (González Salazar, ibíd.).

walachuco. $f$. 1151. |wilachuqu|. s. La sangre que se recibe cuando se mata un carnero se sancocha y sirve para comer con cancha, papas y otras comidas.

En esta palabra, el primer segmento wala deriva de wila 'sangre', existente en aimara y jacaru; en cuanto a <chuco>/chuqu/, no está clara su significación en este contexto porque normalmente significa 'sombrero' o 'gorro'. Una segunda propuesta de interpretación respecto a este componente vería en <chuco> una forma apocopada del adjetivo jacaru chúkupa 'rojo'; entonces tendríamos wala (< wila) 'sangre' y chuku $(<$ chukupa) 'roja', de donde walachuco podría significar 'sangre roja'. < JAC. /walachuku/ </wilachuku/.

waluscar. $f .1151 \mathrm{r}$ /waluskarl. $f .1151 \mathrm{r}$. Se dice a la menudencia del carnero o llama wakada que por un descuido de no lavarlo a tiempo está en principios de descomposición, pero que todavía puede comerse.

En algunas zonas de los Andes peruanos, aplican el adjetivo 'oliscada' a la carne en que ha iniciado la descomposición pero que aún es comestible. En el Diccionario de la Academia, la tercera acepción de oliscar dice "Dicho de una persona o de una cosa: Ofrecer indicios de determinada condición." En este caso, se refiere a indicios de descomposición. Y <waluscar> refleja dos cambios: /o/ > /wa/ (primera sílaba) e /i/ > /u/ (segunda sílaba). < Castellano.

wallke. $f$. 1162r. |wallki|. Bolsón de cuero que usan los hombres y lo cargan como morral, este bolsón siempre tiene divisiones para la cal, coca y otras cositas. $\| 2$. wallki. f. 1049r. Bolsita para depositar la coca. En la documentación lexicográfica antigua del aimara se registra huallquipo. Bolsa de indio ( $c f$. Torres Rubio, 
1616); igualmente, huallquepo. bolsa de indios ( $c f$. Bertonio, [1612] 2006: p.121). Se asocia semánticamente con la voces quechuas registradas en el Anónimo (1586), como "huallca. Collar, saltar de quentas.", "Huallcaricuni. Ponerse collar u otras cosas al cuello." < Q, A *wallki.

wanlla. $f$. 1153. Era en la que se hace el tendal de las mazorcas para que se sequen. El tendal del maíz lo clasifican por colores y calidades de grano.

El adjetivo quechua wanlla designa los granos o tubérculos más grandes o de mejor calidad (AMLQ 2005), lo que se confirma en el texto de Tello por la mención de colores y calidades del grano. <*Q. wanlla. washapa $f$. 1151. Aparejo de llamas cargueras, consistente en una sola pieza de varias camas o jergas colchadas.

Esta palabra tiene la raíz quechua washa 'espalda', 'lomo' (cf. Parker y Chávez 1976: p. 190) y sufijo nominal quechua -pa como en asnapa < asna, misk'ipa $<$ misk'i, sisapa < sisa (AMLQ 2005). <*Q wasa.

watana. $f$. 1161r. |watana|. Cinta tejida a manera de marata.

Este vocablo es de origen quechua tal como se comprueba en el Vocabulario Anónimo, 1586, transcrito como "huatana. Soga o cordel con que se ata algo." En esta palabra está la raíz wata- 'amarrar', 'atar', y el sufijo nominalizador instrumental -na, de donde watana significa 'lo que sirve para amarrar'. Este vocablo se asocia con el verbo watani. Echar lazos o liar o atar. huatanan. s. cabrestro o soga o cordel. ( $c f$. Gonçález Holguín [1608 (1952)] 1989: 186). < Q. */watana/.

weklo $f$. 1151 . |weqlu| s. Se designa a las varitas que están tronchadas o torcidas al natural y no conservan su rectitud.

A continuación, para confirmar la procedencia o filiación del étimo, se cotejará esta información con la de las fuentes lexicográficas del siglo XVI y las contemporáneas, tanto del quechua como del aru. En el Arte y Vocabulario en la Lengua General del Perú de Antonio Ricardo (1586), se registra la voz vecro /wiqru/ 'cosa tuerta' o 'comba' ( $c f$. Vilcapoma, J.C. 2018). Igualmente, un dato asociado lo encontramos en la documentación lexicográfica actual: en Lira \& Mejía (2008) se incluye la alternancia wéqru wéqro y definen: "Patituerto, torcido o zafado hacia un lado. ( $c f$.
Lira \& Mejía, 2008: p. 561); finalmente, en Itier (2017), se incluye el adjetivo weqru. torcidos los pies, la nariz (quechua chanca) y en el quechua inca colla 'torcido solo los pies o las manos' ( $c f$. Itier, 2017: p. 242). De modo que no hay duda de que estamos ante un étimo de origen quechua. La cercanía con el quechua huanca, explicaría la presencia de la lateral. La modificación vocálica así como el aspecto ortográfico es producto de una adaptación a los patrones vocálicos y ortográficos del castellano. $<*$ Q. /wiqru/.

winko. $f$. 1162r. > Q. |winku|. El mate cortado longitudinalmente en dos hemisferios.

En quechua cuzqueño contemporáneo, se registra la voz winko definiéndola como "Porongo obtenido de cierto calabazo seccionado por la mitad, utilizado para trasegar chicha y otros líquidos. Especie de calabaza oblonga." ( $c f$. Lira y Mejía Huamán, 2008: p. 571). <*Q winku.

\subsection{Indigenismos toponímicos}

antanga.f. 987r. Quebrada cerca de Lahuaitambo Prov. de Huarochirí.

En este topónimo se distinguen la raíz aimara anta 'cuesta' (Layme 2004) y el sufijo nominal quechua -nka, que encontramos en el quechua chanca tikanka (< tika) y en el quechua de Huánuco <chacranca> (< chacra) (Wise 1998a).

huascayanga. $f .1015 \mathrm{r}$. 'cerro situado en el ayllu de Lupu Mui elevado' [del Keshua huasca, soga; yanka, $\operatorname{larga}]^{15}$.

En este topónimo, está claro el primer elemento $<$ huasca $>$, que significa 'soga', pero <yanga $>$ resulta difícil de interpretar porque si recurrimos al quechua encontramos yanqa 'mentira' y en el aimara yanqha 'malo', que semánticamente no parece que tengan mucha pertinencia (resultarían 'soga falsa' en quechua o 'soga mala' en aimara). Por descarte, nos queda como opción adoptar la glosa 'larga' que Tello asigna a <yanga>, que es confirmada en Gonçález Holguín con "Yancana [...] Grandazo o largazo demasiado de largo y angosto que excede"; y así tendríamos que $<$ huascayanga $>$ significa 'soga larga', compuesto en que se identifica como núcleo al sustantivo huasca 'soga', seguido del adjetivo que opera como modificador, en este caso, yanka con el significado de 'larga'. Para un mejor escrutinio y comprobación de la filiación linguiística y etimológica de este topónimo, centraremos la atención en la voz toponímica 
<waskayanga> que aporta Tello, la cual, como puede advertirse, es bastante semejante al que estamos analizando, y designa a otra de las entidades geográficas en el territorio huarochirano; y esta vez aparece como una variante ortográfica, respecto al primero:

<waskayanga> $f .1142$ r. Pampa punal muy frígida por la nevada común el frío le hace temblar al que menos.

En este caso, observamos que Tello solo nos proporciona su descripción o designación y ya no la filiación lingüística porque sería la misma que asignó a la variante <huascayanga>. Si tomamos en cuenta la descripción y filiación lingüística quechua que Tello asigna a <huascayanga> y que según él es válida para <waskayanga>, quedaría por confirmar la procedencia quechua de ambos componentes que estructuran estos dos topónimos. Al respecto, señalamos que waska 'soga' está presente en todas las variedades del quechua, mientras que <yanga> (/yanka/) no es conocida pero Gonçález Holguín (1608) al registrar Yancana en su Vocabulario pone fuera de duda su existencia y su significado 'largo(a)', pero no su filiación quechua. De alli que propongamos que la palabra yancana podría ser puquina y no quechua, lengua en que 'largo(a)' se expresa con adjetivos como suni $^{16}$ o suytu; por tanto, el topónimo <huascayanga> sería híbrido quechua-puquina. Por otro lado, valdría la pena plantearnos la siguiente pregunta: ¿la conceptualización asignada a estos topónimos son creaciones léxicas motivadas semánticamente? En respuesta, se podría decir que tratándose de una realidad geográfica (en este caso, montañas o cerros muy elevados), el lexema waska se aplica a cerros o cadenas de cerros, y así tenemos en el norte Huascarán y en el sur Vizcatán (donde <Vizca> viene de /wiska/, variante de /waska/).

sangallaya. $f$.1161.Nombre de uno de los aillos donde existió el apellido Canchupoma, actualmente extinguido.

Según la información de los pobladores de Santa Eulalia, Julio C. Tello nació en las chacras de Cornaya, que forma parte de la jurisdicción de Sangallaya, una de las tierras productivas más planas, al igual que las de Huarochirí pueblo.

Para explicar la procedencia del topónimo, tenemos "sankha. s. Sima, abismo, sitio u hoyo profundo" (Lira \& Mejía 2008), más los sufijos de aplicación nominal - lla (diminutivo o expletivo) y -ya (ver tataya, chanchaya y canchaya). La significación de este nombre de lugar sería 'Lugar de zanja profunda'.

\section{Comentarios y reflexiones}

Siguiendo la documentación temprana como crónicas y relaciones diversas recogen información y mencionan que en las provincias de Huarochirí y Canta se hablaba una 'lengua particular', que se identificaba como idioma del grupo aru, la cual se había extendido presumiblemente a esas regiones por invasores de la vecina provincia de Yauyos. (cf. Torero, 1970). Asimismo, en la Historia del Nuevo Mundo, Cobo (1892) señala lo siguiente:

[...] residiendo los Incas en la ciudad del Cuzco, que siempre tuvieron por cabeza y corte de su Imperio, desde allí lo señalaban y partían en las cuatro susodichas provincias ó regiones, conforme caían hacia las cuatro partes del Mundo; y en cada una déllas se comprendían otras muchas provincias menores de naciones distintas en lengua, trajes y costumbres. Tenían también estas cuatro partes del reino sus nombres propios tomados de las provincias más principales [...]. ( $c f$. Bernabé Cobo 1892: p. 218)

De allí que, por una parte, la filiación lingüística de los indigenismos expuestos en el presente estudio respondan a componentes nominales y verbales provenientes del quechua (en su variedad sureña), del jacaru (bastante similares a los que todavía se escuchan en el distrito de Tupe) y aimara; por otra parte, la temática de este material léxico se constituye en un testimonio e índices del vocabulario indigenista utilizado por quienes formaron parte de las naciones diversas que existieron antiguamente en Huarochirí y Yauyos, y de la relación que establecían entre la lengua y cultura. En ella se comprueba, por un lado, una visible relación con las costumbres, actividades cotidianas (alimentación, cocina, crianza de los bebés, prendas de vestir), faenas en el campo (agricultura, ganado), rituales, que reflejan haber sido parte de prácticas culturales de sus antepasados, conceptualizadas a partir de las experiencias y percepciones de los hablantes en ese contexto histórico, en el antiguo Huarochirí; por otro lado, se infiere que el contacto con las otras naciones condicionó la variación dialectal del quechua. 
En el caso de los indigenismos verbales, se han remodelado siguiendo patrones silábicos y ortográficos del castellano ${ }^{17}$. Se han registrado palabras con acento esdrújulo cuando son trisilábicas; por ejemplo, f. 115. waláchica, cóchica; f. 1153, wáchiga y mákuma.

El material aportado por el arqueólogo y humanista Julio C. Tello es un aporte para comprender los procesos fonéticos fonológicos que se han generado en esta región así como parte de los aspectos morfológicos al entrar en contacto con el castellano.

\section{Conflictos de intereses}

Los autores firmantes del presente trabajo de investigación declaran no tener ningún potencial conflicto de interés personal o económico con otras personas $\mathrm{u}$ organizaciones que puedan influir indebidamente con el presente manuscrito.

\section{Contribuciones de los autores}

Preparación y ejecución; Desarrollo de la metodología; Concepción y diseño; Edición del artículo; Supervisión del estudio: EE.

\section{Bibliografía}

ACADEMIA MAYOR DE LA LENGUA QUECHUA (2005). Diccionario Quechua Español-Quechua / Qheswa-Español-Qheswa / Simi Taqe. Cusco, segunda edición.

ADELAAR, Wilhem. (1994). La procedencia dialectal del manuscrito de Huarochirí en base a sus características lingüísticas. Revista Andina, Año 2, N. ${ }^{\circ}$, Lima.

Blas VALERA [1586]. Arte y Vocabvlario. En la lengva general del Perv llamada quichua, y en la lengua española por Antonio Ricardo Año MDLXXXVI. Editado por Vilcapoma, José Carlos (2018).

ARRIZABALAGA-LIZÁRRAGA, Carlos (2017). Análisis del Glosario de peruanismos de Rubén Vargas Ugarte (1953). En M. Martos y M. Lovón (Eds.), Léxico, ideología y diccionario (pp. 191-223). Lima: Institución Peruana de Promoción Educativa y Cultural.

BELLEZA, Neli (1994). Vocabulario jacarucastellano/castellano-jacaru. Cuzco: C.E.R.A. Bartolomé de Las Casas.

BERTONIO, Ludovico ([1612] 1996). Vocabulario de la Lengua Aymara. Centro de Estudios de la Realidad Económica y Social. Lima, IFEA.
CALVO PÉREZ, Julio (2014). Diccionario etimológico de palabras del Perú. URP. Lima-Perú.

CASADO VELARDE, Manuel (1991). Lenguaje y Cultura. La Etnolingüística. Madrid. Editorial Síntesis.

CERRÓN-PALOMINO, Rodolfo (2004). Las etimologías toponímicas del Inca Garcilaso. Revista Andina. Lima- Perú.

CERRÓN-PALOMINO, Rodolfo (2008b). Voces del Ande. Ensayos sobre onomástica andina. Lima: Fondo Editorial de la PUCP.

CERRÓN-PALOMINO, Rodolfo (2008). Voces del Ande. Ensayos sobre onomástica andina. Fondo Editorial PUCP.

CONSEJO EDUCATIVO DE LA NACIÓN QUECHUA (CENAQ) (s/f). Qhichwa Suyup Simi Pirwan Diccionario de la Nación Quechua, s/l, Consejo Educativo de la Nación Quechua (CENAQ). Es un diccionario boliviano disponible en internet publicado entre $2000 \mathrm{y}$ 2010, posiblemente en Cochabamba, sede del CENAQ.

CUENCA, MARÍA Joseph y Joseph HILFERTY (1999). Introducción a la Lingüística Cognitiva. Barcelona, Editorial Ariel.

ESCOBAR ZAPATA, Emérita (2017). «La semántica cognitiva y los esquemas-imagen en el sistema fitonímico de los jacaruhablantes». Lengua y Sociedad, 15(2), 35-61. CILA- UNMSM. Lima - Perú.

ESCOBAR ZAPATA, Emérita (2017). El sistema fitonímico de los pueblos de Tupe y Cachuy. Un enfoque etnolingüístico. Tesis doctoral. UNMSM. Lima- Perú. https://hdl.handle. net/20.500.12672/6420.

ESCOBAR ZAPATA, Emérita (2017). El Jacaru. Último Relicto Aru en los Andes Centrales. Ed. Agraria. UNALM. Lima-Perú.

ESCOBAR ZAPATA, Emérita (2020). El sistema antroponímico en el tiempo de los incas. Revista Tierra Nuestra Vol. 14. N. ${ }^{\circ}$ 2. UNALM. Lima Peru.

FERNÁNDEZ GORDILLO, Luz (2009). Determinación del concepto de mexicanismo y su identificación en los diccionarios académicos en Nueva Revista de Filología Hispánica Vol. LVII, N. ${ }^{\circ}$ 2. México.

FERRELL RAMÍREZ, Marco (2007). Sufijos en jacaru. Revista-habla. 
GÓMEZ DE SILVA, Guido (2001). Diccionario Breve de Mexicanismos. Academia Mexicana de la Lengua.

https://www.academia.org.mx/obras/obras-deconsulta-en-linea/diccionario-breve-demexicanismos.

GONÇÁLEZ HOLGUÍN, Diego ([1608] 1952, 1989). Vocabulario de la lengva general de todo el Perv llamada lengua Qquichua o del Inca. UNMSM. Lima- Perú.

GONZÁLEZ SALAZAR, Claudia Pamela (2018). Estudio etnolexicográfico de la ganadería y la Fiesta de la herranza en el distrito de Tupe, Lima, Universidad nacional Mayor de San Marcos, Facultad de Letras y Ciencias Humanas. Tesis de Licenciatura.

GUTIÉRREZ CAMACHO, Leoncio; MANTILLA GUTIÉRREZ, Leonidas; HUAMAN JULLUNILA, Shara (2007). Apurimaqpaq Runasimi Taqe / Diccionario de Quechua Apurimeño (Versión Preliminar). Abancay. En

https://es.slideshare.net/waqanky/dic-apurimacquechua

Recuperado en Lima, 16-02-2017 a las 13: $24 \mathrm{~h}$.

ITIER, César (2017). Diccionario quechua sureño castellano. Editorial Commentarios. Lima.

JIMÉNEZ DE LA ESPADA, Marco (1892). Historia del Nuevo Mundo por el Padre Bernabé Cobo. Tomo III. Sevilla - España.

LAYME PAYRUMANI, Félix (2004). Diccionario Bilingüe Aymara-Castellano, La Paz, 3. a edición Consejo Educativo Aymara (CEA).

LIRA, Jorge y MEJÍA HUAMÁN, Mario (2008). Diccionario Quechua-Castellano CastellanoQuechua. Lima, Editorial Universitaria de la Universidad Ricardo Palma.

LUCCA, Manuel de (1987). Diccionario Práctico Aymara-Castellano Castellano-Aymara, La Paz-Cochabamba, Los Amigos del Libro.

MOLINER, María (2008). Diccionario de uso del español. Editorial Gredos. Madrid-España.

NÚÑEZ VARGAS, Leopoldo (1992). "Reseña Histórica del Ayllu de Japaní de la Comunidad Campesina "Santiago de Carampoma" en Huarochirí, ocho mil años de historia. Tomo I. Municipalidad de Santa Eulalia de Acopaya, Lima.
PARKER J., Gary (1976). Gramática quechua ÁncashHuailas, Lima, Instituto de Estudios Peruanos y Ministerio de Educación.

PARKER J., Gary y CHÁVEZ, Amancio (1976). Diccionario quechua Áncash-Huailas, Lima, Instituto de Estudios Peruanos y Ministerio de Educación.

PUITS TARRAGS, Esteban (2007). Breve diccionario folklórico piurano. Facultad de Humanidades de UDEP. Perú.

SANTO THOMÁS, Domingo de (1560). Lexicón o Vocabvlario de la Lengua General del Perv, Valladolid, Impresor Francisco Fernández de Cordoua.

SOLÍS, Gustavo (1999). La lengua culle revisitada en Escritura y Pensamiento. Año II, N. ${ }^{\circ} 4$. UNMSM. Lima.

TAYLOR, Gerald (2008). Ritos y tradiciones de Huarochirí. Lima, Instituto Francés de Estudios Andinos, IEP.

TORERO, Alfredo ([1985] 2007). El quechua y la historia social andina. Lima, Fondo Editorial del Pedagógico de San Marcos.

TORRES RUBIO, Diego de (1616). Arte de la lengua aymara. Lima, Francisco del Canto Editor.

WISE, Mary Ruth (1998a). Rimaycuna / Quechua de Hиánuco, Lima, Institutto Lingüístico de Verano.

WISE, Mary Ruth (1998b). Rimaycuna / Quechua del Huallaga, Lima, Institutto Lingüístico de Verano.

\section{ANEXOS}

\section{Símbolos y abreviaturas utilizados}

// Las barras oblicuas indican una representación fonológica.

L Los corchetes angulados se emplean para encerrar representaciones grafémicas.

\| Las barras perpendiculares se emplean para las formas interpretadas.

( ) Los paréntesis indican el carácter opcional.

$>\quad$ Significa que lo que precede cambia.

$<\quad$ Significa que lo que precede deviene de.

$\sim \quad$ Significa forma variable o alternancia.

* forma reconstruida.

f. folio.

Aim. Aimara.

DST Domingo de Santo Tomás. 
Q. Quechua

1 En todo el mundo, actualmente existen alrededor de 7000 lenguas y de todas ellas, alrededor de un 40 por ciento están en peligro de extinción si las políticas lingüísticas no se fortalecen con los nuevos recursos tecnológicos que pueden cumplir una función importante en su recuperación.

2 Dominaba varias lenguas y su lengua materna, sin duda, era un dialecto aru. Tenía un perfecto dominio de la variante de la lengua general, manejada en la provincia y conocía seguramente los dialectos quechua locales, que constituyen el sustrato del manuscrito.

3 En la obra "Huarochirí: Ocho mil años de historia" (1992), se informa que "el hombre huarochirano de los tiempos arqueológicos es quien [...] pone nombres a los cerros, parajes, altipampas, quebradas, pastos, arbustos, puquios y cursos de agua, nombra a la fauna, avifauna, etc., convirtiendo por último a ciertas moles rocosas como lugares transidos de sacralidad: Cinco cerros, Anchicocha, Condorwasi, Condorcoto, el Cerro Campana".

4 Parte de esta información se presentó como ponencia en el XI Coloquio de lenguas y culturas en los andes "Augusto Escribens Trisano". Investigaciones lingüísticas y Literarias, realizado el 16 de julio del 2021, y, organizado por la Cátedra Quechua de la UNMSM.

5 Igualmente, Peter Van Dale, quien me aceptó mi solicitud para investigar la información en los Archivos de J. C. Tello (UNMSM), cuando era Director de este lugar.

6 En el Diccionario de Americanismos, los indigenismos se definen como "lexemas autóctonos de América y, en caso de haberlos, sus derivados" (cf. DA.2010: XXXI -XXXII).
JAC. Jacaru.

7 Diccionario de la lengua española.

8 De los poblados de San Damián, Lahuastama, Lahuaytambo y Langa.

9 En el DRAE significa: "arrancar los cardos y otras hierbas perjudiciales de un terreno de cultivo. "Fuimos a escardar el huerto para que no se estropeara la cosecha”. V. transitivo. Separar lo bueno de lo malo, en especial de las cosas no materiales. El sufijo muestra sonorización del segmento velar /q/ > /g/.

11 En la variante <caswar> registrada por Tello se constata el cambio del /p/ > /w/.

12 Un dato importante nos proporciona Parker (2013), quien en las reconstrucciones anota "*čakma, *čaqma 'tierra virgen o en barbecho; roturar la tierra para el cultivo" ( $c f$. Parker 2008: p. 97). La segunda forma la asigna al protoquechua cuzqueño; la primera al protoquechua central asi como al ayacuchano. Maíz tierno que se tuesta y se muele después. Con él se prepara comida, en especial, pepián.

14 Deviene de la forma original */sara/ maíz.

15 Corchetes nuestros.

16 Se citó en Escobar, E. (1992).

17 Igualmente, en el culle se observan casos similares, donde se usan recursos similares, voces léxicas reacomodadas con una estructura del infinitiva del castellano. Por ejemplo, cachachar, 'asar algún alimento a medias'; cheguear, 'recoger las papas más grandes durante la cosecha'; cururushar, 'sonido que produce el cuy cuando la hembra está en celo'; cushquir, 'roer algo duro en los animales' y ñushquear, 'espesar el guiso' ( $c f$. Isabel Pantoja 2000). 